\title{
Regenerative Braking Control Strategy of Hydraulic In-wheel Motor Drive System for Heavy Truck
}

\author{
Guanghan $\mathrm{Li}^{1, \mathrm{a}}$, Bing Pan ${ }^{2, \mathrm{~b}}$, Dafeng Song ${ }^{1, \mathrm{c}}$, Sheng $\mathrm{Li}^{3, \mathrm{~d}}$, Gongke Yang ${ }^{4, \mathrm{e}}$ and \\ Yanping $\mathrm{Niu}^{5, f^{*}}$
}

${ }^{1}$ State Key Laboratory of Automotive Simulation and Control, Jilin University, Changchun 130025, China.

\author{
2 Textile fiber inspection, Dongying 257000, China. \\ ${ }^{3}$ FAW Jiefang Automotive Co., Ltd ., Qingdao 266043, China. \\ ${ }^{4}$ Guangzhou automobile group component Co., Ltd ., Guangzhou 510000, China. \\ ${ }^{5}$ Hohhot Vocational College, Hohhot 010051, China.

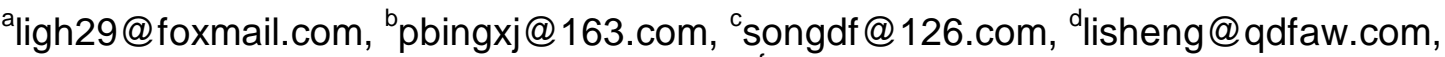 \\ eygk2014@163.com, yp.niu@163.com \\ * Corresponding author: Tel: +86043185094866; Fax: +86043185094866
}

\begin{abstract}
Keywords: Vehicle engineering; Regenerative braking control strategy; Hydraulic in-wheel motor drive system; Heavy truck; Brake force distribution.

Abstract. This paper introduces the configuration and operation principle of the hydraulic in-wheel motor drive system for heavy truck. According to the regenerative braking function of the system, the distribution algorithm of braking force is proposed and a regenerative braking control strategy is developed on the basis of driving cycle of heavy trucks and limits of braking regulations. Finally, the simulation model is built in the MATLAB/Simulink and AMESim platform and the co-simulation is conducted to verify the proposed regenerative braking strategy. The results show that the strategy could realize effective recovery of braking energy, and the maximum recovery rate could be 58\%, which would significantly improve the fuel economy of the heavy truck.
\end{abstract}

\section{Introduction}

Under the burden of the environmental pollutions and energy shortages problems, developing hybrid technology represents an effective approach for its excellent advantages over conventional vehicles in fuel economy and emissions. In recent years, the Hydraulic In-wheel Motor Drive System (HIMDS) has been one of the advanced hydraulic hybrid technology applied into the medium and heavy commercial vehicles because it is more effective and efficient than traditional hybrid systems on the heavy duty vehicles [1,2].

Through the application of the HIMDS, the driven wheels will be changed into driving wheels for a moment when vehicles are in the bad condition roads, which could make full use of traction, and then the vehicle power performance and passing ability are improved[3,4,5]. When braking, the HIMDS could realize regenerative braking function through the hydraulic regenerative braking circuit composed by the secondary component Hydraulic Pump/Motor (HPM) and the Hydraulic Accumulator (HA). The recovery braking energy would be stored in the HA and released while driving, which could reduce wear of traditional braking system, improve braking safety and realize good fuel economy and emissions effectively.

Regenerative braking is an important technology of the hydraulic hybrid vehicles. However, most of investigations to regenerative braking control of the hydraulic hybrid systems are concentrated on Series Hydraulic Hybrid Vehicle (SHHV) and Parallel Hydraulic Hybrid Vehicle (PHHV). The effect of system parameter in SHHV with hydrostatic regenerative braking was studyed [6]. The energy saving mechanism of the braking energy recovery system of PHHV was introduced [7], and a 
mathematic model of composite braking was established [8]. Considering the effects of vehicle load weight and propulsion mode on regenerative braking performance, a regenerative braking control strategy for PHHV was proposed [9]. Overall, the current investigations are lack of exploration to the regenerative braking control of HIMDS, which is the key to energy saving of the commercial vehicles equipped the HIMDS. This paper analyses the operating principles and working characteristics of the HIMDS. Considering the Economic Commission of Europe (ECE) regulations and the driving cycles of heavy trucks, a regenerative braking control strategy is proposed for the HIMDS on the basis of a three-axle heavy commercial truck, and the control algorithm is verified through MATLAB/Simulink and AMESim co-simulation platform.

This paper is organized as follows. Section 2 introduces the configuration and operating principle of the HIMDS. Section 3 proposes the regenerative braking control strategy. Simulations of the control strategy are described in Section 4, and the conclusion is given in Section 5.

\section{Configuration and operating principle of HIMDS}

The configuration sketch of the HIMDS is shown in Fig.1, which are mainly consisted of secondary component HPM, hydraulic variable pump, high pressure HA and low pressure HA. The secondary component HPM, as the key component for energy conversion of the HIMDS, has a high specific power, small volume and four quadrant operating characteristics [10,11]. And the HAs, as the system energy storage element, has high power density and good performances of charging and discharging, which would be very suitable for heavy vehicles [12].

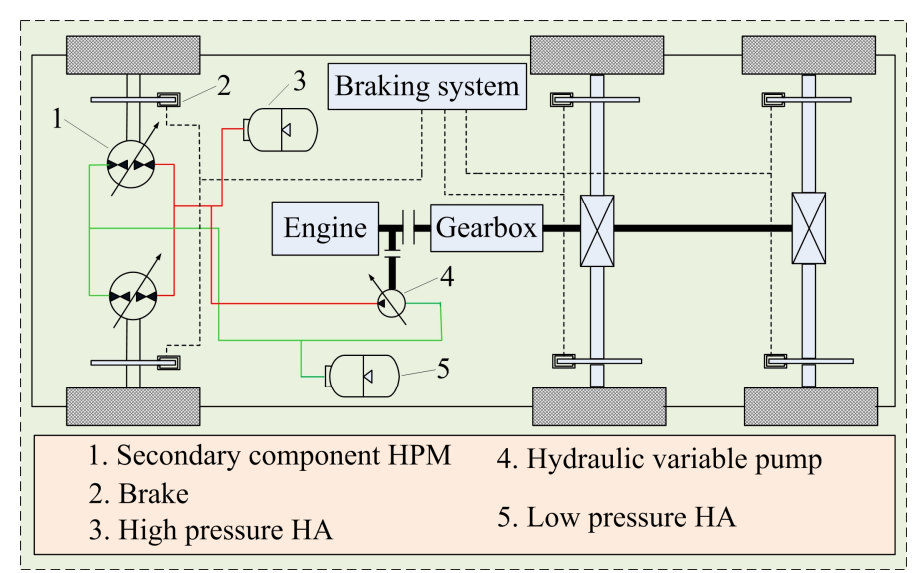

Fig. 1 Configuration of HIDMS

The HIMDS can achieve auxiliary driving and regenerative braking function. When the truck operates on the auxiliary driving mode, the HPM operates as a hydraulic motor. The front wheel is changed from driven wheel into driving wheel, and the truck is in the all-wheel drive state. While on the braking mode, the HPM works as a hydraulic pump, which would be driven by the vehicle kinetic energy. Meanwhile, the HPM drives the hydraulic oil at closed hydraulic circuits from low pressure HA into high pressure HA, and then mechanical energy is converted into hydraulic energy. When the truck starting or accelerating, the energy which is stored in the HA could be released for auxiliary driving, and the power performance and fuel economy are improved. Furthermore, when the vehicle is under the continuous long slope, the HIMDS could play a retarder role, which could reduce the brake force provided by traditional braking system and decrease the operating frequency of brake, and then the braking security is promoted.

\section{Regenerative braking control strategy of HIMDS}

Braking force distribution algorithm. When the three-axle vehicle bakes, the braking force distribution has an important effect on the braking stability [13], and the ECE R13 braking regulations have the 
explicit stipulation [14]. According to the limits of the regulations, the braking force distribution algorithm of the truck at different braking severity is as follows.

When the braking severity $z<0.15$, the ECE R13 braking regulation has no clear requirements for the braking force distribution. The pure regenerative braking is preferential for use in which the braking force is provided by the HIMDS completely. However, if the regenerative braking force can not meet the braking demand, the traditional mechanical frictional braking force will supplement the rest.

When the braking severity $z>0.15$, the composite braking will be adopted. The demand braking force is primarily distributed to the front, middle and rear axle based on the distribution coefficient. And the braking force of front axle is composed of regenerative and frictional braking force. The detailed of the distribution algorithm is shown in Eq.1 to Eq.3.

$$
\begin{aligned}
& \left\{\begin{array}{l}
z \leq 0.15 \& F_{b x} \leq F_{r e g} \\
F_{b x_{-} f}=F_{b x}=F_{r e g} ; F_{b x_{-} m}=F_{b x_{-} r}=0
\end{array}\right. \\
& \left\{\begin{array}{l}
z \leq 0.15 \& F_{b x}>F_{r e g} \\
F_{b x_{-} f}=F_{r e g}+\beta_{1} \Delta F ; F_{b x_{-} m}=\beta_{2} \Delta F ; F_{b x_{-} r}=\beta_{3} \Delta F \\
\Delta F=F_{b x}-F_{r e g}
\end{array}\right. \\
& \left\{\begin{array}{l}
z>0.15 \\
F_{b x_{-} f}=\beta_{1} F_{b x}=F_{r e g}+F_{f r c} ; F_{b x_{-} m}=\beta_{2} F_{b x} ; F_{b x_{-} r}=\beta_{3} F_{b x}
\end{array}\right.
\end{aligned}
$$

Where $F_{b x}$ is the demand braking force; $F_{r e g}$ is the regenerative braking force; $F_{f r c}$ is the frictional braking force of front axle; $F_{b x_{-} f}, F_{b x_{-} m}$ and $F_{b x_{-} r}$ are the demand braking force at front, middle and rear axle, respectively. $\beta_{1}, \beta_{2}$ and $\beta_{3}$ are the distribution coefficient of the braking force of front, middle and rear axle, respectively. 


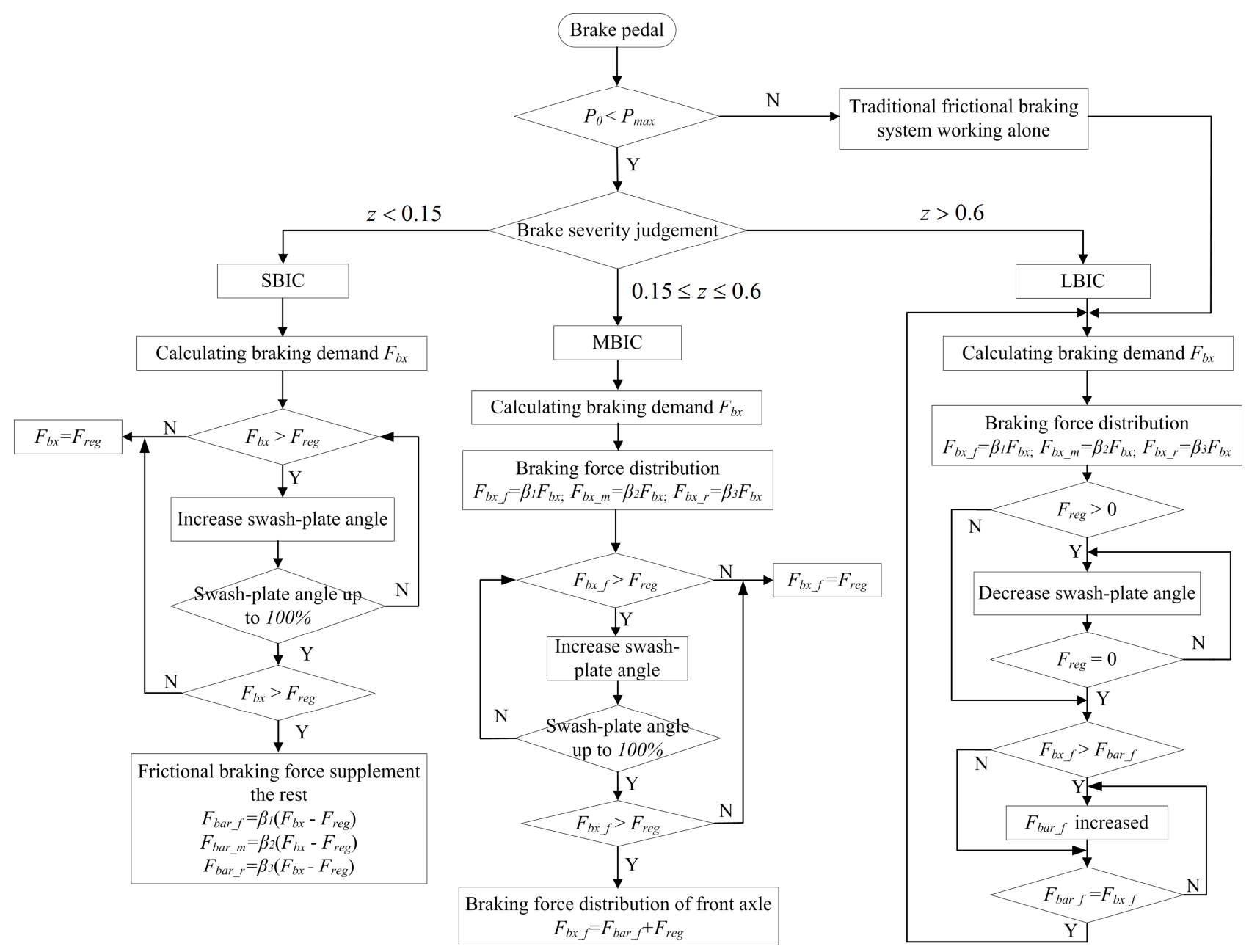

Fig. 2 Regenerative braking control strategy of HIDMS

Regenerative braking control strategy of HIMDS. Three different braking conditions are primarily defined according to the target brake severity, and then the regenerative braking control strategy of the HIMDS is developed for the corresponding braking conditions. The definition of the braking condition is as follows.

When the brake severity $\mathrm{z}<0.15$, define the condition as the Small Braking Intensity Conditions (SBIC). When $0.15<\mathrm{z}<0.6$, the definition is Moderate Braking Intensity Conditions (MBIC) and otherwise is the Large Braking Intensity Conditions (LBIC).

The regenerative braking control strategy of the HIMDS is shown in Fig.2. When brake pedal is pushed by the driver, the braking control unit will judge $P_{0}$, the initial pressure of the accumulator, firstly. When $P_{0}$ is less than $P_{\max }$, which is the maximum operating pressure of the accumulator, the regenerative braking function of the HIMDS is started. Otherwise, the traditional braking system will work alone. And then the controller will determine the brake severity and enter the corresponding control mode.

During SBIC and MBIC braking mode, the braking process is the same with the description of the braking force distribution algorithm according to the braking severity, and the regenerative braking force is conrolled by the swash-plate angle of the HPM. While in the LBIC mode, the target braking severity is big which could be supposed to be emergency braking condition. Considering the security and stability of the braking, the HIMDS would exit, and the braking demand will be meet by traditional frictional braking system completely. 


\section{Model development of HIMDS and simulation validation}

Model development. In order to verify the effectiveness of regenerative braking control strategy of the HIMDS, the control algorithm and the vehicle model are built in the Matlab/Simulink and the hydraulic system model is established in the AMESim. And then offline simulation and analysis are carried out through the AMESim and MATLAB/Simulink co-simulation platform. Framework of the simulation model is shown in Fig.3.

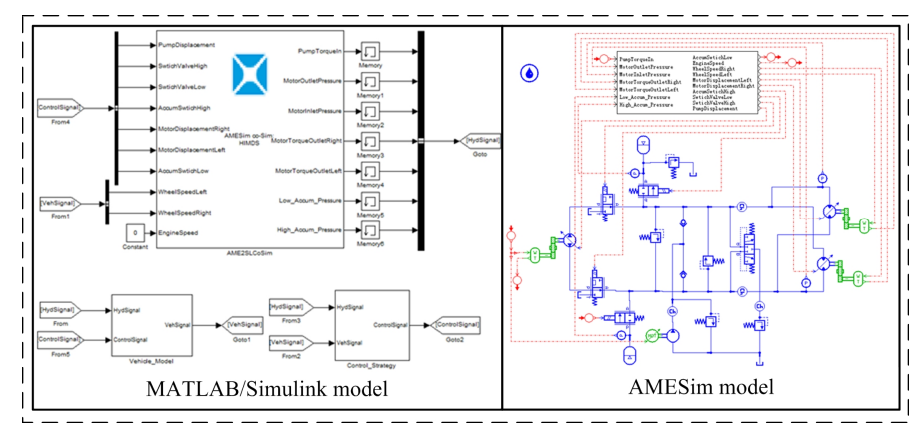

Fig.3 Framework of HIMDS simulation model

Simulation analysis. Considering the average speed of the heavy trucks is relatively low and referring the initial braking speed commonly used by the heavy truck driving cycles, such as UDDSHDV, NYCTRUCK, CSHRV and WVUSUB, etc., two kinds of initial speed are determined in the simulation, $15 \mathrm{~m} / \mathrm{s}$ and $10 \mathrm{~m} / \mathrm{s}$ respectively. In addition, SBIC $(\mathrm{z}=0.1)$ and MBIC $(\mathrm{z}=0.2)$ braking conditions are selected in the paper, since the regenerative braking function of the HIMDS do not work at the LBIC. And road adhesion coefficient is set to 0.8 . The basic parameters of the heavy truck are shown in Table 1.

Table 1 Vehicle parameters

\begin{tabular}{ccc}
\hline & Parameters & Values \\
\hline & Complete vehicle shipping mass [kg] & 14820 \\
Vehicles & Axle base [mm] & 4500 \\
& Rolling radius [mm] & 544 \\
& Frontal area $\left[\mathrm{m}^{2}\right]$ & 6.7 \\
Air drag coefficient & 0.8 \\
HPM & Rolling resistance coefficient & 0.008 \\
& Type & Poclain MS hydraulic motor \\
& Displacement $\left[\mathrm{cm}^{3} \cdot \mathrm{r}^{-1}\right]$ & 1043 \\
& Volume $[\mathrm{L}]$ & 50 \\
& Initial pressure [Mpa] & 10 \\
\hline
\end{tabular}

The simulation result of $15 \mathrm{~m} / \mathrm{s}$ initial braking speed at SBIC mode is shown in Fig.4, including the speed change, accumulator state change and braking torque change. The accumulator state contains Accumulator Pressure (AP) and Accumulator Volume (AV) and Accumulator Recovery Energy (ARE), and the braking torque contains Front axle Frictional Braking Torque (FFBT), Middle axle Frictional Braking Torque (MFBT), Rear axle Frictional Braking Torque (RFBT) and Front axle Regenerative Braking Torque (FRBT). 


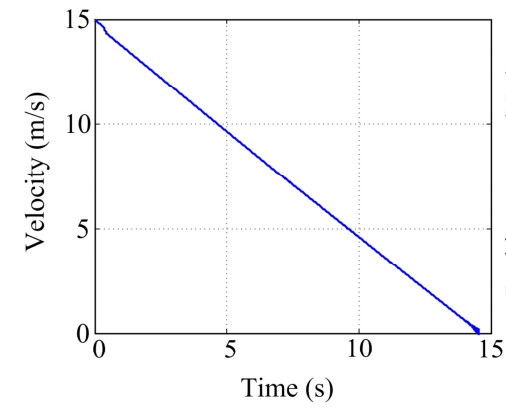

(a) Vehicle velocity

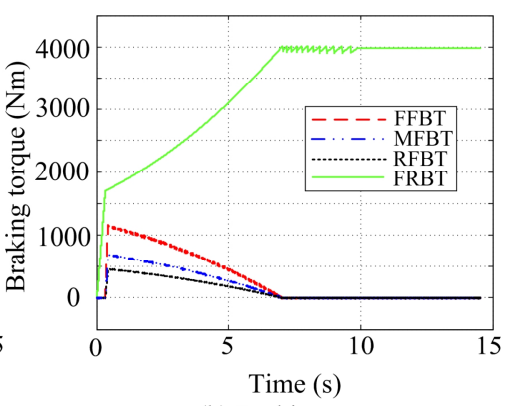

(b) Braking torque

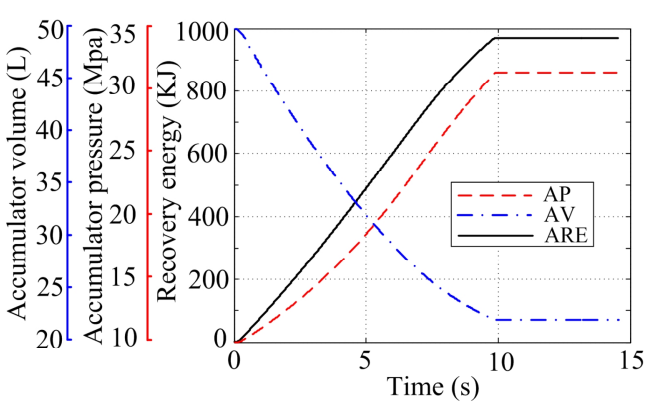

(c) Accumulator state

Fig.4 Simulation results at SBIC, $15 \mathrm{~m} / \mathrm{s}$

As shown in Fig.4, the traditional mechanical frictional braking system has to operate to compensate for the insufficient braking force at initial time, as the hydraulic regenerative braking force can not meet the braking requirement. With the accumulator pressure increasing, the regenerative braking force is also increasing and mechanical braking force decreasing. About at $6.5 \mathrm{~s}$, the mechanical braking is down to zero and the regenerative braking system could maintain the braking deceleration alone. When the accumulator pressure is up to $31.5 \mathrm{Mpa}$, the relief valve in the HIMDS begins to work to maintain the hydraulic circuit pressure, and the braking energy recycled by accumulator reaches to maximum. During the process of SBIC, the accumulator can recycle braking energy $970 \mathrm{KJ}$ and the recovery rate is $58 \%$.

The simulation result of $10 \mathrm{~m} / \mathrm{s}$ initial braking speed at SBIC mode is shown in Fig.5. The braking process is similar to the above. However, according to the accumulator pressure curves, the pressure rises slowly due to the low initial braking speed, which lead to the FRBT is smaller than the braking process of $15 \mathrm{~m} / \mathrm{s}$.

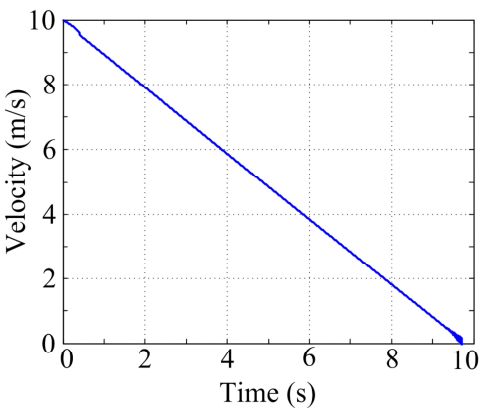

(a) Vehicle velocity

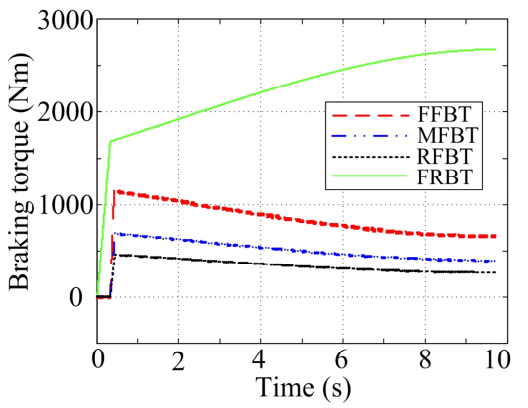

(b) Braking torque

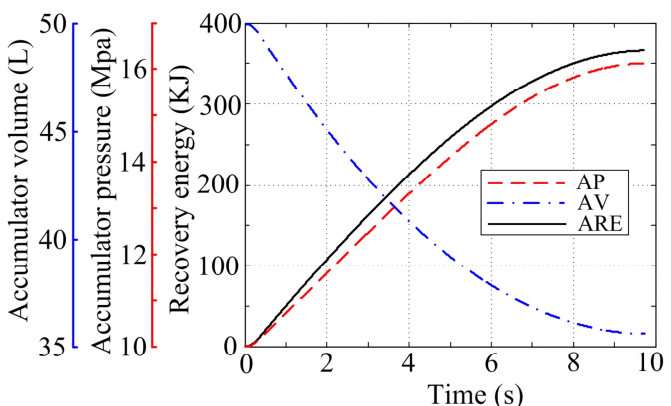

(c) Accumulator state

Fig.5 Simulation results at SBIC, $10 \mathrm{~m} / \mathrm{s}$

In addition, the speed of recovering braking energy is slower in the braking process. And at the end of the process, the accumulator pressure does not reach to the maximum. Therefore, the recovery energy in the process decreases, about $366 \mathrm{KJ}$, and the energy recovery rate is $49 \%$.

The simulation result of $15 \mathrm{~m} / \mathrm{s}$ initial braking speed at MBIC mode is shown in Fig.6. Before the braking severity up to 0.15 , the control strategy at SBIC is selected. While the brake severity exceeds 0.15 , the control strategy transfers from SBIC to MBIC. At the beginning of the transition, the mechanical frictional braking force rises rapidly from steady state and achieves the stable value ultimately. In addition, the braking process can recycle braking kinetic energy 466KJ and the energy recovery rate is $28 \%$. 


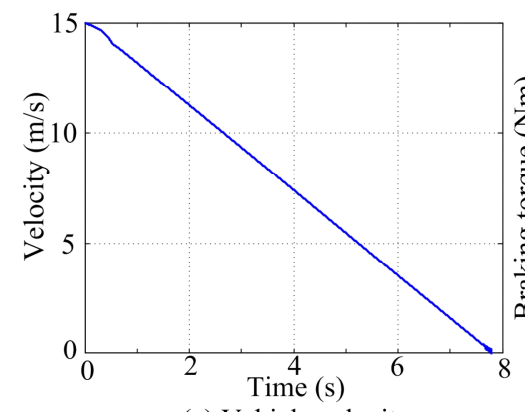

(a) Vehicle velocity

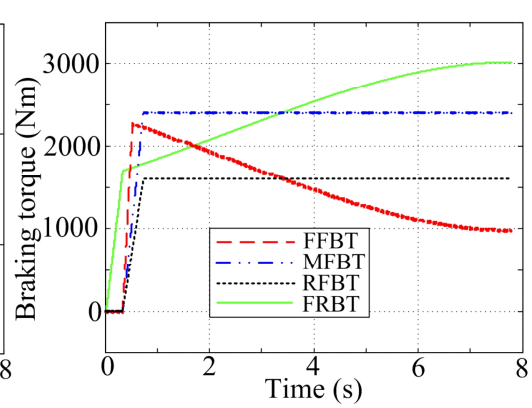

(b) Braking torque

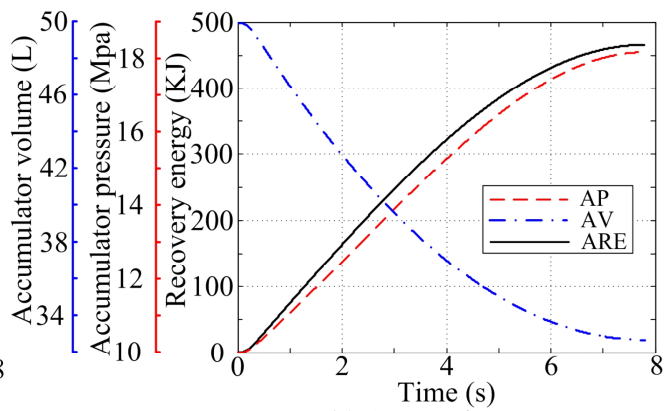

(c) Accumulator state

Fig. 6 Simulation results at MBIC, $15 \mathrm{~m} / \mathrm{s}$

The simulation result of $10 \mathrm{~m} / \mathrm{s}$ initial braking speed at MBIC mode is shown in Fig.7. According to the simulation results, this process also achieves the smooth transition control from SBIC to MBIC. And this braking process can recycle braking kinetic energy $180 \mathrm{KJ}$ and the energy recovery rate is $24 \%$.

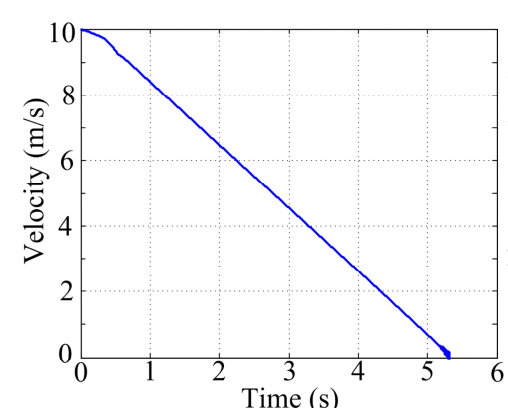

(a) Vehicle velocity

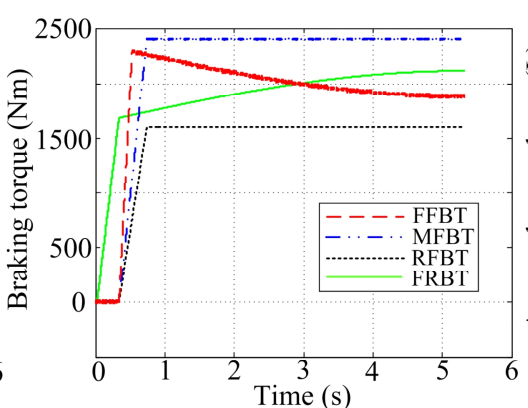

(b) Braking torque

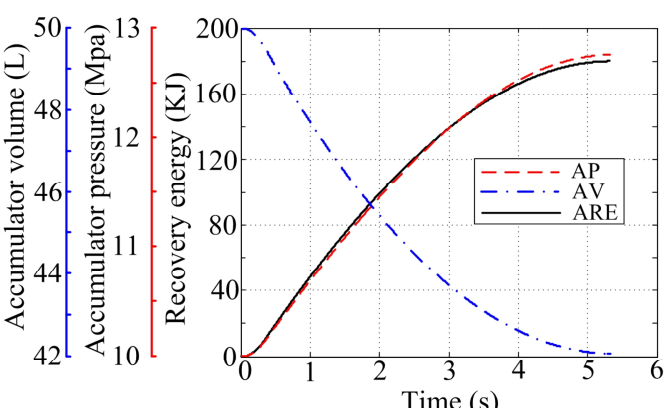

(c) Accumulator state

Fig.7 Simulation results at MBIC, $10 \mathrm{~m} / \mathrm{s}$

Table 2 Comparison of braking energy recovery in different braking conditions

\begin{tabular}{cccc} 
Braking condition (brake severity/velocity $[\mathrm{m} / \mathrm{s}]$ ) & Recovery energy [KJ] & Recovery rate [\%] \\
\multirow{2}{*}{ SBIC } & 15 & 970 & 58 \\
& 10 & 366 & 49 \\
\multirow{2}{*}{ MBIC } & 15 & 466 & 28 \\
& 10 & 180 & 24 \\
\hline
\end{tabular}

The comparison of the braking energy recovery in different braking conditions is shown in Table.2, and braking force distribution algorithm of SBIC could recycle maximum braking energy and the energy recovery rate can be up to 58\%. Furthermore, during the operating process of the heavy commercial vehicles, the SBIC is occurred with high-frequency. Therefore, the energy recovery rate and environmental protection property of the heavy commercial vehicle can be significantly improved through the regenerative braking control strategy at SBIC.

\section{Conclusions}

The proposed regenerative braking control strategy of the HIMDS not only can ensure stability and security of vehicles during braking but also can recovery energy effectively, and the maximum energy recovery rate can be up to 58\%, which has made up for the deficiency of the research on the HIMDS.

The recovery braking energy could be used to drive the vehicles, which could reduce the engine load and the emissions, and improve the fuel economy. The investigation will be significant for the development of the environment-friendly heavy trucks. 


\section{Acknowledgements}

This project is supported by National Natural Science Foundation of China (NSFC No. 51305155 , 51075179), Scientific Frontier and Interdisciplinary Merit Aid Projects of Jilin University, China (No. 2013ZY08)

\section{References}

[1] Niu Feng. MAN developed new front wheel drive system for heavy truck-Hydra-Matic driving system. Automobile \& Parts, 44(2006) 44-45. (In Chinese)

[2] Information on http://www.poclain-hydraulics.com/en/systems/trucks

[3] He Hui. Study on modeling and control strategy of Hydraulic In-wheel Motor drive system for heavy truck. Master thesis, Jilin University, 2014. (In Chinese)

[4] He Hui, Song Da-feng, Yang Nan-nan, et al. Control and simulation of hydraulic in-wheel motor propulsion system. Journal of Jilin University (Engineering and Technology Edition), 42 (S1) (2012) 27-31. (In Chinese)

[5] Li Sheng, Song Da-feng, Zeng Xiao-hua, et al. Modeling and simulation of hydraulic wheel motor propulsion system for heavy truck. Transactions of the Chinese Society for Agricultural Machinery, 43(4) (2012) 10-14. (In Chinese)

[6] Ramakrishnan R, Hiremath S S, Singaperumal M. Theoretical investigations on the effect of system parameters in series hydraulic hybrid system with hydrostatic regenerative braking[J]. Journal of mechanical science and technology, 26(5) (2012) 1321-1331.

[7] Dong Han, Liu Xin-hui, Wang Xin, et al. Parallel hydraulic hybrid braking regenerative characteristics. Journal of Jilin University (Engineering and Technology Edition), 44(6) (2014) 1655-1663. (In Chinese)

[8] Liu T, Zheng J, Su Y, et al. A Study on Control Strategy of Regenerative Braking in the Hydraulic Hybrid Vehicle Based on ECE Regulations. Mathematical Problems in Engineering, 2013.

[9] Liu Tao, Jiang Ji-hai, Sun Hui. Research on regenerative braking control strategy for parallel hydraulic hybrid vehicles based on backward modeling. Chinese Journal of Mechanical Engineering, 20(15) (2009) 1880-1884. (In Chinese)

[10] Kim Y J, Filipi Z. Simulation study of a series hydraulic hybrid propulsion system for a light truck. SAE Technical Paper, 2007.

[11] Baseley S, Ehret C, Greif E, et al. Hydraulic hybrid systems for commercial vehicles. SAE Technical Paper, 2007.

[12] Wang Xin. Research on energy saving and control performances of wheel drive hydraulic hybrid vehicle. PhD thesis, Harbin Institute of Technology, 2010. (In Chinese)

[13] Tong Chengqian. Study on analysis method of braking performance for multi-axle automobile based on ECE regulation. Master thesis, Jiangsu University, 2010. (In Chinese)

[14] He Yuping, Lun Jingguang. Review on foreign and domestic braking regulation of passenger cars. Automotive Engineering, 16 (3) (1999) 182-192. (In Chinese) 